\title{
Effect of transcranial direct current stimulation (tDCS) over the prefrontal cortex combined with cognitive training for treating schizophrenia: a sham-controlled randomized clinical trial
}

\author{
Efeito da estimulação transcraniana por corrente contínua (ETCC) sobre o \\ córtex pré-frontal combinada a treinamento cognitivo para o tratamento da \\ esquizofrenia: ensaio clínico randomizado simulação controlado
}

Pedro Shiozawa, ${ }^{1}$ July Silveira Gomes, ${ }^{1,2}$ Daniella Valverde Ducos, ${ }^{1,2}$ Henrique Teruo Akiba, ${ }^{1,2}$ Álvaro Machado Dias, ${ }^{2}$ Alisson Paulino Trevizol, ${ }^{1}$ Ricardo R. Uchida, ${ }^{1}$ Natasza Orlov, ${ }^{3}$ Quirino Cordeiro ${ }^{1}$

\begin{abstract}
Introduction: We report a transcranial direct current stimulation (tDCS) protocol over the dorsolateral prefrontal cortex (DLPFC) combined with cognitive training in schizophrenia.

Method: We assessed psychotic symptoms in nine patients using the Positive and Negative Syndrome Scale (PANSS). All evaluations were scored at baseline, at the end of the intervention protocol, and during a 4-week follow-up. The tDCS protocol consisted of 10 consecutive sessions over 5-day periods. We placed the cathode over the right and the anode over the left DLPFC. For sham stimulation, we turned the device off after 60 seconds. Cognitive training consisted of the administration of $\mathrm{N}$-back and sequence learning tasks.

Results: We performed an analysis of covariance (ANCOVA) to adjust for the dependent variable PANSS, considering the interaction with baseline severity scores $(p=0.619)$. Mixed analysis of variance (ANOVA) showed no statistical significance between the groups regarding final PANSS scores.

Conclusion: The results failed to demonstrate that the concomitant use of tDCS and cognitive training is effective to improve clinical outcomes in patients with schizophrenia. The present findings should be analyzed with care, considering the small sample size. Larger controlled trials on electric/cognitive stimulation should be produced in order to enhance therapeutic strategies in schizophrenia.
\end{abstract}

Keywords: Schizophrenia, cognition, transcranial direct current stimulation.

\section{Resumo}

Introdução: Descrevemos os resultados de protocolo de estimulação transcraniana por corrente contínua (ETCC) sobre o córtex pré-frontal dorsolateral combinado a treinamento cognitivo para o tratamento de esquizofrenia.

Métodos: Avaliamos os sintomas psicóticos em nove pacientes utilizando a Positive and Negative Syndrome Scale (PANSS). As avaliações foram realizadas antes, ao fim do protocolo de tratamento, e após 4 semanas de seguimento. O protocolo de ETCC consistiu em 10 sessões consecutivas em períodos de 5 dias. 0 cátodo foi posicionado à direita e o ânodo à esquerda sobre o córtex pré-frontal dorsolateral. Para estimulação simulada, o equipamento foi desligado após 60 segundos. $O$ treinamento cognitivo consistiu na administração de tarefas $\mathrm{N}$-back e aprendizado sequencial. Resultados: Utilizamos análise de covariância (ANCOVA) ajustada à variável dependente PANSS, considerando a interação com a gravidade antes da ETCC ( $p=0.619)$. A análise de variância (ANOVA) não mostrou diferença significativa entre os grupos em relação à PANSS final. Conclusão: Os resultados falharam em demonstrar que o uso concomitante de ETCC e treinamento cognitivo é efetivo na meIhora do desfecho clínico em pacientes com esquizofrenia. Os achados devem ser avaliados com cuidado, considerando a amostra pequena. Estudos maiores sobre estimulação elétrica/cognitiva devem ser produzidos a fim de melhorar estratégias terapêuticas na esquizofrenia.

Descritores: Esquizofrenia, cognição, estimulação transcraniana por corrente contínua.

\footnotetext{
${ }^{1}$ Centro Interdisciplinar de Neuromodulação Clínica, Faculdade de Ciências Médicas da Santa Casa de São Paulo, São Paulo, SP, Brazil. ${ }^{2}$ Laboratório Interdisciplinar de Neurociências Clínicas, Universidade Federal de São Paulo (UNIFESP), São Paulo, SP, Brazil. ${ }^{3}$ Institute of Psychiatry, King's College London, London, United Kingdom.

Financial support: none.

Submitted Aug 24 2015, accepted for publication Apr 12 2016. No conflicts of interest declared concerning the publication of this article.

Suggested citation: Shiozawa P, Gomes JS, Ducos DV, Akiba HT, Dias AM, Trevizol AP, et al. Effect of transcranial direct current stimulation (tDCS) over the prefrontal cortex combined with cognitive training for treating schizophrenia: a sham-controlled randomized clinical trial. Trends Psychiatry Psychother. 2016;38(3):175-177. http://dx.doi.org/10.1590/2237-6089-2015-0043
} 


\section{Introduction}

Transcranial direct current stimulation (tDCS) devices send a direct low current to the brain through two electrodes - anode and cathode - increasing and decreasing cortical excitability. Studies reveal that induced cortical excitability may have not only polaritydependent effects, but also intensity-dependent effects (i.e., greater effects associated with higher current doses), which can last many days beyond the period of stimulation. ${ }^{1,2}$ We present a tDCS protocol over the dorsolateral prefrontal cortex (DLPFC) combined with cognitive training in schizophrenia.

\section{Method}

We performed a double-blind study in which 10 subjects were selected and randomized by computer software based on a simple randomization method. All patients were diagnosed with schizophrenia according to criteria of the Diagnostic and Statistical Manual of Mental Disorders, 5th edition (DSM-5) and were under pharmacotherapy. Written informed consent was provided (institutional review board-approved). Psychotic symptoms were assessed with the Positive and Negative Syndrome Scale (PANSS). ${ }^{3}$ Participants completed the estimated intelligence quotient (IQ) provided by two subtests of the Wechsler Adult Intelligence Scale-Third Edition (WAIS-III) ${ }^{4}$ : matrix reasoning (fluid intelligence index) and vocabulary (crystallized intelligence index). All evaluations were scored at baseline, at the end of the intervention protocol, and during a 4-week followup. We also evaluated depressive symptoms using the Calgary scale s $^{5}$ in order to verify possible convergences of improvements in depressive symptoms and psychotic symptoms. We designed the present study to assess the effect of the concomitant use of tDCS and cognitive training over clinical symptoms in schizophrenia. Our primary aim was to investigate a possible improvement in cognitive performance. We considered other clinical features as secondary outcomes.

The tDCS protocol consisted of 10 consecutive sessions over 5 -day periods, with a minimum interval of 3 hours between sessions. The cathode was placed over the right DLPFC and the anode over the left DLPFC. ${ }^{6,7} \mathrm{We}$ used a direct current of $2.0 \mathrm{~mA}$ for 20 minutes. The 35 $\mathrm{cm} 2$-rubber electrodes were wrapped in cotton material moistened with saline solution to reduce impedance. For sham stimulation, the device was set to turn off after 60 seconds (study mode). Cognitive training was based on the administration of $\mathrm{N}$-back and sequence learning tasks, ${ }^{8}$ which were randomly applied during one of the
tDCS sessions. The tests were computerized for easy and repeated administration.

Data distribution was based on histogram analysis. We chose to run parametric tests for all data as to guarantee a more conservative analysis - considering that the use of parametric tests even for non-normal data would not determine an increase of type I error. We adopted regression analysis to assess the main clinical outcome using PANSS scores as dependent variables (overall, positive, negative and general dimensions) at the end of the stimulation protocol. Post-hoc analysis was performed with multiple correlation tests to verify the existence and strength of positive or negative relationships between different variables. Further linear regressions were also tested in an attempt to model the relationship between two or more explanatory variables and a response variable. Finally, the issue of multicollinearity was addressed and revealed a variance inflation factor lower than 10, indicating lack of collinearity.

\section{Results}

One participant in the study missed a session due to transportation problems. All patients were under adequate pharmacological therapy. Moreover, all of them were using atypical antipsychotic medication. Six patients were on olanzapine (up to $20 \mathrm{mg} /$ day), two patients were on risperidone (up to $6 \mathrm{mg} /$ day), and one patient was on aripiprazole ( $30 \mathrm{mg} /$ day). Patients also reported irregular use of benzodiazepines (clonazepam up to $2 \mathrm{mg} /$ day) due to sporadic insomnia. No other psychiatric drug was reported. Sixty-six percent ( $n$ $=6$ ) of the patients were female, and mean age was $35.6 \pm 8.2$ years. Patients presented no other clinical or psychiatric comorbidity.

Data analysis showed that baseline PANSS scores were related to final results $(p=0.001)$. However, the use of cognitive therapy combined with tDCS showed no relation with changes in clinical scores. The analysis of covariance (ANCOVA) used to adjust for the dependent variable (final PANSS scores) and having the intervention (sham vs. active group) as the independent variable, considering the interaction with baseline severity scores, did not show statistical significance $(p=0.619)$. Mixed analysis of variance (ANOVA) also failed to show statistical significance between the groups regarding final PANSS scores. Correlation analysis showed that the baseline PANSS score was negatively correlated with the significant outcomes of the tasks performed on the first day ( $\mathrm{N}$-back: $\mathrm{rs}[6]=-0.762, \mathrm{p}=0.028$; sequence learning: $r s[6]=-0.723, p=0.043$ ), but not with IQ test 
( $\mathrm{N}$-back: $r s[6]=-0.247, \mathrm{p}=0.555$; sequence learning: $\mathrm{rs}[6]=-0.242, \mathrm{p}=0.564)$. All patients reported mild transient paresthesia over the stimulated area. No other adverse effect was reported (Table 1 ).

Table 1 - Regression analysis with final PANSS scores as the dependent variable

\begin{tabular}{lcc}
\hline & $\mathbf{9 5 \%} \mathbf{C I}$ & $\mathbf{p}$ \\
\hline Overall PANSS & & \\
Intervention & -17.37 to 11.43 & 619 \\
Baseline PANSS & 0.2267563 to & $0.018^{*}$ \\
Positive dimension & 1.555144 & \\
& & \\
Intervention & -3.528451 to & 351 \\
& 8.235871 & \\
Baseline PANSS & 0.0211014 to & $0.039 *$ \\
Negative dimension & 0.5634967 & \\
Intervention & -12.66779 to & \\
& 6.209952 & 419 \\
Baseline PANSS & -0.2592387 to \\
General dimension & 0.6111218 & 346 \\
Intervention & -16.60934 to & \\
& 7.526705 & 378 \\
Baseline PANSS & 0.1145761 to & 970 \\
\hline
\end{tabular}

$95 \% \mathrm{CI}=95 \%$ confidence interval; PANSS $=$ Positive and Negative Syndrome Scale.

$* p<0.05$.

\section{Discussion}

Results failed to demonstrate that the concomitant use of tDCS and cognitive training is effective to improve cognitive performance and other clinical outcomes in patients with schizophrenia. The reasons for this negative outcome may be the interference effect between competitive brain areas - i.e., those being stimulated versus those required for the task - or the characteristics of the sample - low IQ, imbalance of symptoms between the groups and small sample size, which may have reduced the statistical power to detect differences between the groups. That said, one may speculate whether some sort of neutralization effect occurs from superposition. According to Baddeley's working memory model, 6 attending to a specific cognitive task implies the neural suppression of task-irrelevant stimuli, which also means the suppression of other cognitive tasks that are not being intentionally executed by the subject.
The picture that emerges of someone's brain while attending to a cognitive task is thus of selective activation. In contrast, when applied conventionally (patients at rest), tDCS produces a relatively diffuse activation of the brain. ${ }^{9}$ This activation may be hampered by task-induced suppression of other groups of neurons, especially during the performance of a novel or undertrained task. ${ }^{10}$

We suggest that the present findings be taken with caution since our sample size was small. Low-powered studies may produce more false negatives than highpowered ones. Therefore, larger controlled trials should be performed in order to enhance therapeutic strategies for schizophrenia.

\section{References}

1. George MS, Aston-Jones G. Noninvasive techniques for probing neurocircuitry and treating illness: vagus nerve stimulation (VNS), transcranial magnetic stimulation (TMS) and transcranial direct current stimulation (tDCS). Neuropsychopharmacology. 2010;35:301-16.

2. Shiozawa P, Fregni F, Bensenor IM, Lotufo PA, Berlim MT, Daskalakis JZ, et al. Transcranial direct current stimulation for major depression: an updated systematic review and metaanalysis. Int J Neuropsychopharmacol. 2014;17:1443-52.

3. Kay SR, Fiszbein A, Opler LA. The positive and negative syndrome scale (PANSS) for schizophrenia. Schizophr Bull. 1987;13:26176.

4. Crawford JR, Allum S, Kinion JE. An index-based short form of the WAIS-III with accompanying analysis of reliability and abnormality of differences. Br J Clin Psychol. 2008;47:215-37.

5. Addington D, Addington J, Schissel B. A depression rating scale for schizophrenics. Schizophr Res. 1990;3:247-51.

6. Shiozawa $P$, da Silva ME, Cordeiro $Q$, Fregni F, Brunoni AR. Transcranial direct current stimulation (tDCS) for catatonic schizophrenia: a case study. Schizophr Res. 2013;146:374-5.

7. Kurimori $M$, Shiozawa $P$, Bikson $M$, Aboseria $M$, Cordeiro $Q$ Targeting negative symptoms in schizophrenia: results from a proof-of-concept trial assessing prefrontal anodic tDCS protocol. Schizophr Res. 2015;166:362-3.

8. Averbeck BB, Evans S, Chouhan V, Bristow E, Shergill SS. Probabilistic learning and inference in schizophrenia. Schizophr Res. 2011;127:115-22

9. Yuan P, Raz N. Prefrontal cortex and executive functions in healthy adults: a meta-analysis of structural neuroimaging studies. Neurosci Biobehav Rev. 2014;42:180-92.

10. Miniussi $C$, Harris JA, Ruzzoli $M$. Modelling non-invasive brain stimulation in cognitive neuroscience. Neurosci Biobehav Rev. 2013;37:1702-12

\section{Correspondence:}

Alisson Paulino Trevizol.

Departamento de Psiquiatria, Faculdade de Ciências Médicas da Santa Casa de São Paulo

Rua Major Maragliano, 241, Vila Mariana

04017-030 - São Paulo, SP - Brazil

Tel.: + 55 (11) 3466.2100

E-mail: alisson.trevizol@hotmail.com 